\title{
Hepatitis A: Clinical Manifestations and Management
}

\author{
Sook-Hyang Jeong ${ }^{a}$ Hyo-Suk Lee $^{b}$ \\ ${ }^{a}$ Department of Internal Medicine, Seoul National University Bundang Hospital, and ${ }^{b}$ Department of Internal \\ Medicine, Liver Research Institute, Seoul National University College of Medicine, Seoul, Korea
}

\section{Key Words}

Clinical manifestation - Hepatitis A virus • Korea •

Management $\cdot$ Prognosis

\begin{abstract}
Due to improved living conditions and subsequent changes in hepatitis A epidemiology, the disease burden of hepatitis $A$ is increasing in many regions. Recently, Korea has faced a large, community-wide outbreak of hepatitis A, which has prompted a vaccination program. The clinical spectrum of hepatitis $A$ virus infection ranges from asymptomatic infection to fulminant hepatitis. Clinical manifestations depend on the age of the host: less than $30 \%$ of infected young children are symptomatic, while about $80 \%$ of infected adults manifest severe hepatitis with remarkably elevated serum aminotransferases. Fulminant hepatitis is rare, with a reported incidence from 0.015 to $0.5 \%$. Atypical manifestations include relapsing hepatitis and prolonged cholestasis, and complicated cases with acute kidney injury have been reported. Extrahepatic manifestations, such as autoimmune hemolytic anemia, aplastic anemia, pure red cell aplasia, pleural or pericardial effusion, acute reactive arthritis, acute pancreatitis, acalculous cholecystitis, mononeuritis, and Guillain-Barré syndrome, have been rarely reported. Management of hepatitis A includes general supportive care, and critical decisions regarding liver transplantation await further studies on prognostic predictors. Fundamental man-
\end{abstract}

agement of hepatitis $A$ is active vaccination. However, a vaccination program should be adapted to the regional situation, according to differing epidemiology and disease burden.

Copyright $\odot 2010$ S. Karger AG, Basel

\section{Introduction}

Hepatitis A virus (HAV), a positive-strand RNA virus, is stable at moderate temperature and low $\mathrm{pH}$, allowing the virus to survive in the environment and be transmitted by the fecal-oral route [1]. Although a highly effective and safe vaccine for hepatitis A was developed in the early 1990s, HAV is still an important etiology of acute viral hepatitis worldwide. Clinical manifestations of hepatitis A depend on the age of the host: less than $30 \%$ of infected young children showed symptomatic hepatitis, while about $80 \%$ of infected adults manifest as severe acute hepatitis with remarkably elevated serum aminotransferases [2].

According to changes in socioeconomic status and improved living conditions, many developing countries are experiencing an epidemiological shift of HAV infection, which has resulted in the development of many cases of adult hepatitis A. Recently, Korea has faced a large community-wide outbreak of hepatitis $A$, with a relative shortage of vaccine [3]. The vaccination program for hep-

\section{KARGER}

Fax +4161306 1234

E-Mail karger@karger.ch

www.karger.com
(C) 2010 S. Karger AG, Basel

0300-5526/10/0531-0015\$26.00/0

Accessible online at:

www.karger.com/int
Hyo-Suk Lee, MD

Department of Internal Medicine, Liver Research Institute

Seoul National University College of Medicine

28 Yungun-dong, Chongno-gu, Seoul 110-774 (Korea)

Tel. +82 2745 7557, Fax +82 2743 6701, E-Mail hsleemd@ snu.ac.kr 
atitis $\mathrm{A}$ is ever changing according to the increasing number of cases of fulminant hepatitis $\mathrm{A}$ and cases requiring urgent liver transplantation (LT).

The aim of this review is to describe the clinical manifestations and management of hepatitis A, including vaccination strategy, within the current status of hepatitis A in Korea.

\section{Hepatitis A Virus}

HAV is a non-enveloped, single-stranded RNA virus classified in the Picornaviridae family and in the Hepatovirus genus. It is stable at low $\mathrm{pH}$ and resistant to moderate heat, allowing the virus to survive in the environment, and it can be transmitted by the fecal-oral route [1] The RNA genome of HAV is positive-sense (i.e. translatable), $7.5 \mathrm{~kb}$ in length, and consists of a large open reading frame with a $5^{\prime}$ noncoding region (nucleotides 734-740 form the internal ribosome entry site) and a 3 ' noncoding region. The aminoterminal third of the viral genome encodes the major capsid proteins, and the remaining two thirds encode nonstructural proteins largely required for viral replication [4]. Viral proteins are translated and proteolytically processed by viral protease.

After ingestion, virions reach the liver in the portal blood and are taken up by hepatocytes. In hepatocytes, virus particles replicate, assemble, and are secreted into the biliary canaliculus, from which they pass into the bile duct and small intestine. The enterohepatic cycles of the virus life cycle continue until neutralizing antibodies and other immune mechanisms interrupt the cycle [1].

Following infection, a large number of virions shed in the feces, surviving on human hands and inanimate objects. Contact with a person infected with hepatitis $\mathrm{A}$ is the most common identifiable source of infection [5], and transmission by international travel, injection drug use [6], men having sex with men, and food or waterborne outbreaks [7] have been reported. The largest known epidemic of hepatitis A was from consumption of contaminated seafood in Shanghai, China, where more than 290,000 cases were attributable to eating raw clams [8].

\section{Clinical Manifestations of Hepatitis A}

\section{Typical Clinical Manifestations}

The clinical spectrum of HAV infection ranges from asymptomatic infection to fulminant hepatitis. Clinical manifestations of hepatitis A are dependent on the age of the patient. In children younger than 6 years of age, about $70 \%$ of infections are asymptomatic; in contrast, infection is usually symptomatic, with jaundice and remarkably high levels of serum aminotransferases, in more than $70 \%$ of adult patients [9].

Following a 2-7-week incubation period, typical symptoms develop, including fever, malaise, nausea, vomiting, abdominal discomfort, dark urine, and jaundice. Less common symptoms include myalgia, pruritus, diarrhea, arthralgia, and skin rash. There is no evidence of chronic liver disease or persistent infection after acute hepatitis A. However, some patients show prolonged disease or relapsing disease lasting up to 6 months, with prolonged excretion of HAV. Laboratory tests have shown elevated total bilirubin (mean peak $7 \mathrm{mg} / \mathrm{dl}$ ), alkaline phosphatase (mean peak $319 \mathrm{IU} / \mathrm{l}$ ), serum aspartate aminotransferase of 1,754 IU/l, and alanine aminotransferase of 1,952 IU/l. Clinical illness and laboratory abnormalities recover within 2 months from onset of illness [2].

\section{Atypical Clinical Manifestations}

Atypical manifestations following hepatitis A have been reported. These include relapsing hepatitis, prolonged cholestasis, and complicated cases with acute kidney injury as well as a rare autoimmune hepatitis. Relapsing hepatitis A was characterized by a biphasic peak of serum aminotransferase elevation with 4-7-week intervals between the first and the second peak. Prolonged cholestatic hepatitis A was characterized by pruritus, fatigue, loose stools and weight loss accompanying prolonged cholestasis [9]. Compared to typical cases, prolonged cholestatic cases can be predicted by detection of plasma HAV RNA after 20 days of illness, while relapsing hepatitis remains unpredictable on the basis of plasma HAV determination [10]. Acute kidney injury complicating nonfulminant hepatitis A was found in $1.5-4.7 \%$ of hepatitis A patients. Proposed mechanisms of renal damage include pre-renal factors associated with anorexia, nausea, vomiting, diarrhea and fever as well as nephrotoxic effects of hyperbilirubinemia, immune complexmediated nephritis, interstitial nephritis and (rarely) massive intravascular hemolysis. One study reported that the independent predictors for acute kidney injury development in hepatitis A included lower hematocrit, presence of coagulopathy, high CRP concentration and higher peak bilirubin levels [11].

\section{Other Extrahepatic Manifestations}

There have been rare cases of extrahepatic manifestation of hepatitis A that included autoimmune hemolytic 
anemia, aplastic anemia, pure red cell aplasia, pleural or pericardial effusion, acute reactive arthritis, acute pancreatitis and neurologic complications, such as mononeuritis, mononeuritis multiplex and Guillain-Barré syndrome [9]. Acalculous cholecystitis may often be complicated, as illustrated by an edematous gallbladder on radiological images and compatible clinical findings, many of which manifest transiently with spontaneous recovery.

\section{Fulminant Hepatitis A}

Fulminant hepatitis is a rare complication of hepatitis A, with a reported incidence from 0.015 to $0.5 \%$ of hepatitis A cases. In one study, low serum HAV RNA levels and high bilirubin levels were significantly associated with fulminant hepatitis, which suggests that HAV-related liver failure is due to a vigorous host immune response with a marked reduction in viral load, rather than a direct viral effect [12].

Fujiwara et al. [13] reported that viral strains isolated from fulminant hepatitis showed relatively few nucleotide substitutions in the $5^{\prime}$ noncoding region when compared with a considerable sequence variation in virus strains from nonfulminant hepatitis. Therefore, nucleotide variations in the central portion of the $5^{\prime}$ noncoding region of HAV may influence the severity of hepatitis A [13]. However, a recent study from India reported no evidence of HAV genome variation according to the severity of hepatitis, which warrants further study on the existence of HAV mutations associated with disease severity [14].

Risk for acute liver failure is high among older adults with underlying chronic liver disease. LT may be necessary; however, HAV-related fulminant hepatitis resolves spontaneously more frequently than fulminant hepatitis of other etiologies. Therefore, the decision to transplant or not to transplant is not an easy one. The US Acute Liver Failure Study Group reported that a prognostic index consisting of 4 presenting features (serum alanine aminotransferase $<2,600 \mathrm{IU} / \mathrm{l}$, creatinine $>2.0 \mathrm{mg} / \mathrm{dl}$, intubation, pressors) predicted the likelihood of LT or mortality, which was better than MELD or the King's College criteria [12].

\section{The Situation in Korea}

Recently, Korea has faced a large community-wide outbreak of hepatitis A. According to the sentinel cases reported to the Korea Centers for Disease Control and Prevention, the total number of cases of hepatitis A has increased remarkably in the past 4 years. Our study of 109 cases of hepatitis A showed a mean age of 29 years, and males comprised $59 \%$ of the total. The mean hospital admission period was 6.7 days, which suggests a high medicosocial cost [15].

The number of cases of fulminant hepatitis A requiring LT has also increased in Korea. Results from one study showed that among 35 cases of fulminant hepatitis, $57 \%$ survived without LT, $6 \%$ died without LT, $29 \%$ survived after LT and 9\% died after LT. By multiple logistic regression analysis, the independent prognostic factor for spontaneous survival was the degree of hepatic encephalopathy [16]. An interesting case of recurrent hepatitis A after LT for fulminant hepatitis A in transplanted liver has been reported [17].

\section{Pregnancy}

Hepatitis A during pregnancy is associated with high risk of maternal complications and preterm labor, despite the relatively mild features of the disease. Significant associations were observed between preterm labor and the presence of both fever and hypoalbuminemia, and hepatitis cases were clustered in the third trimester [18]. There was no evidence of mother-child transmission of hepatitis A virus infection, and fetal outcome was benign despite prematurity. Therefore, HAV serology and maternal vaccination during pregnancy evaluation should be considered in areas where susceptible adult populations exist.

\section{Management of Hepatitis A}

\section{General Supportive Management}

There is no specific management for hepatitis A. Supportive care includes adequate hydration, nutritional support, use of antiemetics for severe vomiting, and use of antipyretics for high fever. Cases complicated by fulminant hepatic failure, hepatic encephalopathy, and low factor $\mathrm{V}$ level were marginally related to a history of acetaminophen intake ( $p=0.07)$, although it was not an independent factor for the development of fulminant hepatitis by multivariate analysis [12]. Therefore, acetaminophen administration for control of high fever should be cautious during the symptomatic period of acute hepatitis.

Hemolysis can be precipitated by hepatitis A, particularly in patients with glucose-6-phosphate dehydrogenase deficiency [19]. Moreover, red cell survival can be shortened. Considering that acute kidney injury or hemolytic anemia may complicate hepatitis A, regular renal 
function testing along with complete blood analysis should be performed, with availability of hemodialysis, due to the fact that about half of hepatitis A cases with acute kidney injury need hemodialysis.

In the case of a cholestatic variant of hepatitis A, corticosteroids have been tried in the past; however, persistent elevation of aminotransferase levels and viral excretion with progressive hepatic fibrosis in one patient treated with corticosteroids were reported. Therefore, corticosteroid treatment should be used with caution [9].

\section{Vaccination}

Fundamental management of hepatitis A includes active and passive immunoprophylaxis. The 4 inactivated hepatitis A vaccines available worldwide are safe and effective. A single dose provides excellent short-term protection for up to 2 years in young adults, and the second dose is important for long-term protection [20]. Recommended target populations for the hepatitis A vaccine include persons at increased risk of acquiring infection or of having poor prognosis after infection, such as travelers to high endemic areas, patients with underlying chronic liver disease, hemophiliacs, intravenous drug users and men who have sex with men.

According to several reports, hepatitis A in patients with chronic liver disease has a less favorable course, although not all reported series showed concordantly poor prognosis [21]. However, considering the remarkably high levels of aminotransferase during acute hepatitis A infection in adults, patients with underlying chronic liver disease, particularly those with limited liver function, cannot tolerate such acute, vigorous liver injury. Therefore, vaccination should be offered to patients with chronic liver disease regardless of the etiology.

A vaccination program should be suited to the regional situation, taking into account differing epidemiologies and disease burdens [22]. Among the areas experiencing an epidemiological shift in hepatitis A from high to intermediate endemicity, a universal toddleronly vaccination program in Israel demonstrated high effectiveness, challenging the need for catch-up vaccination programs [23]. Therefore, to reduce morbidity and mortality caused by the recent epidemic of hepatitis A among young adults in Korea, universal vaccination of young children should be implemented as soon as possible. Catch-up vaccination of young adults and adolescents with a single-dose vaccination [24] should also be considered, due to the current vaccine shortage in Korea.
For post-exposure prophylaxis, the classical method was to administer immunoglobulin within 14 days after exposure. However, on the basis of encouraging results from randomized trials comparing the effect of immunoglobulin and hepatitis A vaccine after exposure, the use of hepatitis A vaccine has been preferred over immunoglobulin since 2007. Vaccine as post-exposure prophylaxis provides several advantages over immunoglobulin, including long-term protection, easy administration, and more abundant supply [25].

\section{Conclusion}

HAV remains an important cause of hepatitis outbreak, as do fatal cases of fulminant hepatitis requiring urgent LT. According to changes in HAV epidemiology, the disease burden of hepatitis A has increased in many regions, including Korea, because hepatitis A shows more severe clinical manifestations in adults than in children. Atypical features of hepatitis A include recurrent hepatitis, prolonged cholestasis, acute kidney injury, hemolytic anemia and other extrahepatic manifestations. Management of hepatitis A includes general supportive care and critical decisions regarding LT. Fundamental management of hepatitis A includes active vaccination, and the vaccination program should be suited to the regional situation, according to differing epidemiologies and disease burdens.

\section{Acknowledgment}

This study was, in part, supported by grants from the Korean Association for the Study of the Liver.

\section{Disclosure Statement}

The authors declare that there is no conflict of interest regarding this study. 


\section{References}

-1 Martin A, Lemon SM: Hepatitis A virus: from discovery to vaccines. Hepatology 2006;43:S164-S172.

2 Tong MJ, el-Farra NS, Grew MI: Clinical manifestations of hepatitis A: recent experience in a community teaching hospital. J Infect Dis 1995;171(suppl 1):S15-S18.

$\checkmark 3$ Jeong SH: Current status and vaccine indication for hepatitis A virus infection in Korea (article in Korean). Korean J Gastroenterol 2008;51:331-337.

4 Nainan OV, Xia G, Vaughan G, Margolis HS: Diagnosis of hepatitis A virus infection: a molecular approach. Clin Microbiol Rev 2006;19:63-79.

5 Staes CJ, Schlenker TL, Risk I, Cannon KG, Harris H, Pavia AT, Shapiro CN, Bell BP: Sources of infection among persons with acute hepatitis A and no identified risk factors during a sustained community-wide outbreak. Pediatrics 2000;106:E54.

-6 Grinde B, Stene-Johansen K, Sharma B, Hoel T, Jensenius M, Skaug K: Characterisation of an epidemic of hepatitis A virus involving intravenous drug abusers: infection by needle sharing? J Med Virol 1997;53:69-75.

7 Wheeler C, Vogt TM, Armstrong GL, Vaughan G, Weltman A, Nainan OV, Dato V, Xia G, Waller K, Amon J, Lee TM, Highbaugh-Battle A, Hembree C, Evenson S, Ruta MA, Williams IT, Fiore AE, Bell BP: An outbreak of hepatitis A associated with green onions. N Engl J Med 2005;353:890-897.

$\checkmark 8$ Cooksley WG: Consensus statement on the role of hepatitis A vaccination in patients with chronic liver disease. J Viral Hepat 2000;7(suppl 1):29-30.

9 Cuthbert JA: Hepatitis A: old and new. Clin Microbiol Rev 2001;14:38-58.
10 Sagnelli E, Coppola N, Marrocco C, Onofrio M, Scarano F, Marotta A, Scolastico C, Catuogno A, Salzillo A, Sagnelli C, Piccinino F Filippini P: HAV replication in acute hepatitis with typical and atypical clinical course. J Med Virol 2003;71:1-6.

$>11$ Kim HW, Yu MH, Lee JH, Chang JW, Yang WS, Kim SB, Lee SK, Park JS, Park SK: Experiences with acute kidney injury complicating non-fulminant hepatitis A. Nephrology (Carlton) 2008;13:451-458.

12 Rezende G, Roque-Afonso AM, Samuel D, Gigou M, Nicand E, Ferre V, Dussaix E, Bismuth H, Feray C: Viral and clinical factors associated with the fulminant course of hepatitis A infection. Hepatology 2003;38:613618.

13 Fujiwara K, Yokosuka O, Ehata T, Saisho H, Saotome N, Suzuki K, Okita K, Kiyosawa K, Omata M: Association between severity of type A hepatitis and nucleotide variations in the $5^{\prime}$ non-translated region of hepatitis a virus RNA: strains from fulminant hepatitis have fewer nucleotide substitutions. Gut 2002;51:82-88.

14 Hussain Z, Husain SA, Pasha ST, Anand R Chand A, Polipalli SK, Rehman S, Kar P: Does mutation of hepatitis A virus exist in North India? Dig Dis Sci 2008;53:506-510.

15 Lee D, Cho YA, Park Y, Hwang JH, Kim JW, Kim NY, Lee DH, Lee W, Jeong SH: Hepatitis A in Korea: epidemiological shift and call for vaccine strategy. Intervirology 2008;51:7074

16 Kim JM, Lee YS, Lee JH, Kim W, Lim KS: Clinical outcomes and predictive factors of spontaneous survival in patients with fulminant hepatitis A (article in Korean). Korean J Hepatol 2008;14:474-482.
17 Eisenbach C, Longerich T, Fickenscher H, Schalasta G, Stremmel W, Encke J: Recurrence of clinically significant hepatitis A following liver transplantation for fulminant hepatitis A. J Clin Virol 2006;35:109-112.

18 Elinav E, Ben-Dov IZ, Shapira Y, Daudi N, Adler R, Shouval D, Ackerman Z: Acute hepatitis a infection in pregnancy is associated with high rates of gestational complications and preterm labor. Gastroenterology 2006; 130:1129-1134.

19 Abid S, Khan AH: Severe hemolysis and renal failure in glucose-6-phosphate dehydrogenase deficient patients with hepatitis E. Am J Gastroenterol 2002;97:1544-1547.

20 Bell BP: Hepatitis A vaccine. Semin Pediatr Infect Dis 2002;13:165-173.

21 Almasio PL, Amoroso P: HAV infection in chronic liver disease: a rationale for vaccination. Vaccine 2003;21:2238-2241.

$>22$ Jacobsen KH, Koopman JS: Declining hepatitis A seroprevalence: a global review and analysis. Epidemiol Infect 2004;132:10051022.

$\checkmark 23$ Wasley A, Samandari T, Bell BP: Incidence of hepatitis A in the United States in the era of vaccination. JAMA 2005;294:194-201.

24 Orr N, Klement E, Gillis D, Sela T, Kayouf R, Derazne E, Grotto I, Balicer R, Huerta M, Aviram L, Ambar R, Epstein Y, Heled Y, Cohen D: Long-term immunity in young adults after a single dose of inactivated hepatitis A vaccines. Vaccine 2006;24:4328-4332.

25 Victor JC, Monto AS, Surdina TY, Suleimenova SZ, Vaughan G, Nainan OV, Favorov MO, Margolis HS, Bell BP: Hepatitis A vaccine versus immune globulin for postexposure prophylaxis. N Engl J Med 2007;357: 1685-1694. 